Aletria, Belo Horizonte, v. 28, n. 3, p. 103-119, 2018

(c) (1)

\title{
Um Sexta-Feira que se chamava Dos: Adolfo Bioy Casares e a tradição das literaturas de língua inglesa
}

\section{A Friday Who Was Called Dos: Adolfo Bioy Casares and the Literary Tradition in the English Language}

\section{Letícia Malloy}

Universidade do Estado do Rio Grande do Norte, Assu, Rio Grande do Norte / Brasil leticiamalloy@gmail.com

Resumo: Este artigo tem o objetivo de examinar diálogos entre a tradição das literaturas de língua inglesa, os romances La invención de Morel e Plan de evasión e, notadamente, o conto "Un perro que se llamaba Dos", do escritor argentino Adolfo Bioy Casares. Para isso, toma-se como ponto de partida o contexto de ascensão do romance inglês, em que se verificam mudanças socioculturais engendradas pelo puritanismo, pelo individualismo e pelo capitalismo nascente, e as relações entre tal contexto e o fazer literário. Além de levar em conta aspectos constantes de Robinson Crusoé, de Daniel Defoe, o estudo analisa modulações do romance inglês verificadas em Narrativa de Arthur Gordon Pym, de Edgar Allan Poe, A ilha do tesouro, de Robert Louis Stevenson, e $A$ ilha do dr. Moreau, de H. G. Wells, para refletir sobre suas interlocuções com a narrativa de Adolfo Bioy Casares.

Palavras-chave: Adolfo Bioy Casares; tradição literária; romances de língua inglesa; romance argentino; conto argentino.

Abstract: This article situates the novels La invención de Morel and Plan de evasión and the short story "Un perro que se llamaba Dos" (1967), all by Argentine author Adolfo Bioy Casares, in relation to the rise of the English prose narrative and the novel in the UK and the US. From their beginnings, short stories, novellas, and novels register sociocultural changes engendered by puritanism, individualism, and capitalism. This article references Daniel Defoe's Robinson Crusoe, Edgar Allan Poe's The Narrative of Arthur Gordon Pym of Nantucket, Robert Louis Stevenson's Treasure Island, and H. G. Wells's The Island of Doctor Moreau in establishing a context for an analysis of the form and content of Adolfo Bioy Casares's narrative.

Keywords: Adolfo Bioy Casares; literary tradition; novels in English; Argentine novel; Argentine short story. 
Em estudo publicado em 1957, dedicado ao exame da consolidação do gênero romanesco na Inglaterra do século XVIII, Ian Watt tece considerações sobre as obras de Daniel Defoe, Samuel Richardson e Henry Fielding. Ao tratar do processo de composição levado a cabo por Defoe, Watt toma inicialmente por foco o romance Robinson Crusoé e assevera que a caracterização de seu protagonista resulta, em importante medida, de diálogos entre o fazer literário e mudanças culturais, sociais e religiosas verificadas naquele período histórico. Tais diálogos se fundam na convergência de hábitos e valores fomentados, de um lado, pelo puritanismo e, de outro, pelo individualismo e capitalismo em ascensão. Nos termos de Watt, o personagem de Defoe reúne aspectos do "individualismo puritano", que indicava "o caminho do homem comum para o céu", ${ }^{1}$ e do "individualismo econômico", 2 que apontava àquele mesmo homem a trilha rumo ao êxito material. Um tal arranjo de traços constitutivos do personagem é realçado, também, por Luiz Costa Lima, cujo estudo publicado em 2009 confere maior ênfase ao fato de que os valores espirituais do personagem, quando aventados, atendem ao propósito de justificar ou legitimar as práticas de acúmulo de bens, os frutos do trabalho e o senhorio do náufrago sobre o que está à sua volta. De acordo com Costa Lima, "[...] a espiritualização dos atos do personagem tem uma função bastante pragmática - é a condição para que se expanda seu domínio da ilha." ${ }^{3} \mathrm{Na}$ esteira das considerações de Watt e Costa Lima, o relato dos esforços e empreitadas de Robinson Crusoé pode ser lido como celebração do sujeito e de seus feitos, tendendo estes, no contexto histórico em que Defoe escreveu, a serem estimados como verdadeiros.

No romance publicado em 1719, tido como texto fundador do romance inglês e reconhecido como um dos pilares do gênero romanesco, verifica-se uma preocupação central, consubstanciada na persecução do efeito de autenticidade da matéria narrada. A valorização de um tal efeito se comunica com prioridades à época estabelecidas, em linhas gerais, pelo protestantismo e, de modo mais acentuado, por sua vertente puritana. No contexto do puritanismo inglês, como no das comunidades nascentes da Nova Inglaterra, encorajava-se a escrita de diários de modo a que seu autor pudesse, entrada após entrada, refletir sobre si mesmo.

\footnotetext{
WATT. A ascensão do romance, p. 85.

2 WATT. A ascensão do romance, p. 78.

${ }^{3}$ COSTA LIMA. O controle do imaginário \& a afirmação do romance, p. 278.
} 
Um registro dessa natureza costumava ser organizado para que o diarista o relesse e, nesse exercício, procedesse à avaliação de seu melhoramento espiritual. ${ }^{4}$ Ao puritanismo comprazia a escrita de diários e o acesso a textos cujo conteúdo objetivasse promover a elevação moral dos membros da comunidade. Segundo observa Luiz Costa Lima, coube à tradição puritana incentivar a elaboração de obras "de testemunho e edificação". Desse rol de obras, excluíam-se as de natureza ficcional. Por consequência, uma narrativa como a do náufrago de Daniel Defoe somente poderia desfrutar de êxito junto ao leitor se sua elaboração se fizesse respaldar pelo efeito de autenticidade. ${ }^{6}$

A persecução daquele efeito orienta a matéria do romance desde a seção inicial de Robinson Crusoé, em que se lê o prefácio redigido por um suposto editor do manuscrito. Esse editor busca certificar o leitor quanto à autoridade narrativa daquele viajante, que discorre sobre suas inúmeras peripécias e infelicidades. Busca, ainda, sublinhar o "propósito religioso" e o caráter de utilidade do texto, sugerindo a combinação de sua faceta de entretenimento à qualidade informativa que se poderia encontrar nas "aventuras de um homem comum":

O editor acredita que esta é uma história de fatos verdadeiros; não há nela qualquer aspecto de ficção: e quem imaginar - porque todas essas coisas são discutíveis - que servirá tanto para a distração quanto para a instrução do leitor, que assim seja; e, como tal, acredita o editor estar, sem mais louvores ao mundo, prestando um grande serviço com esta publicação. ${ }^{8}$

${ }^{4}$ BREMER. Puritanism, p. 38; 54.

${ }^{5}$ COSTA LIMA. O controle do imaginário \& a afirmação do romance, p. 267.

${ }^{6}$ Como observa Italo Calvino a respeito da primeira edição de Robinson Crusoé, publicada em 1719, ali "[n]ão aparecia o nome do autor, pois se devia considerá-lo um verdadeiro livro de memórias escritas pelo náufrago." (CALVINO. "Robinson Crusoe", o diário das virtudes mercantis, p. 102).

7 DEFOE. Robinson Crusoé, p. 19.

${ }^{8}$ DEFOE. Robinson Crusoé, p. 19. "The Editor believes the thing to be a just History of Fact; neither is there any Appearance of Fiction in it: And however thinks, because all such things are dispatch'd, that the Improvement of it, as well as the Diversion, as to the Instruction of the Reader, will be the same; and as such he thinks, without farther Compliment to the World, he does them a great Service in the Publication." (DEFOE. Robinson Crusoe, p. 3). 
Uma vez atribuída credibilidade às experiências contadas por Crusoé, o editor se cala e cede a palavra ao narrador-protagonista. Sem qualquer embaraço, a voz e a vontade do personagem atravessam o relato: não se dobram à determinação paterna, na Inglaterra, nem às lágrimas da mãe; não recuam em virtude da viagem malsucedida na costa inglesa, nem do aprisionamento na costa africana; não se acomodam diante de um quadro financeiro favorável em terras brasileiras; não esmorecem após o naufrágio e a longa estadia na ilha deserta; não permitem, ainda, que se questione seu domínio sobre a totalidade do espaço insular. Robinson Crusoé se assenhora daquela porção de terra e para si reclama a condição de "[...] rei e senhor incontestável daquela terra, com direito de posse".

A autoridade do inglês é exercida no processo mesmo de narração da própria história, iniciado com o registro de memórias que remetem a sua juventude e concluído com referências ao regresso do personagem ao continente europeu. Essa autoridade narrativa é potencializada pela disposição, ao centro do texto, de um diário mantido pelo narradorprotagonista durante parte de sua estadia na ilha. Crusoé chama a si as funções de autor, leitor, editor e crítico de suas páginas pessoais. Ao comentar sobre o início da escrita de seu diário, o próprio Crusoé se encarrega de censurar a maneira como redigiu as primeiras passagens ali dispostas. Com isso, não pretende corrigir uma informação ou submeter à prova a veracidade de quaisquer de suas afirmações; objetiva, tão somente, lamentar o tom maçante de alguns dos trechos que havia escrito e deles propor uma nova redação:

Foi então que passei a manter um diário sobre a minha ocupação do dia-a-dia, se bem que, a princípio, eu me encontrasse um tanto impaciente, não apenas por causa do trabalho, mas também por falta de serenidade mental, e o diário, por causa disso, ficou repleto de coisas tediosas. Por exemplo, eu devia ter escrito assim: "30 de setembro. Após chegar à praia e ter escapado de afogamento, em vez de agradecer a Deus pela minha salvação, tendo primeiro vomitado uma grande quantidade de água salgada que havia penetrado no estômago, e recuperando-me um pouco, corri pela praia, torcendo as mãos e golpeando a cabeça e o rosto, esbravejando contra a minha infelicidade e berrando que estava perdido, perdido, até que, exausto

9 DEFOE. Robinson Crusoé, p. 162. “[...] King and Lord of all this Country indefeasibly, [with] a Right of Possession" (DEFOE. Robinson Crusoe, p. 85). 
e debilitado, fui forçado a deitar no chão, para repousar, mas não ousei dormir, por medo de ser devorado." 10

É oportuno notar as repercussões de Robinson Crusoé sobre outros romances insulares, como A narrativa de Arthur Gordon Pym (1838), de Edgar Allan Poe, A ilha do tesouro (1882), de Robert Louis Stevenson, e A ilha do dr. Moreau (1896), de H. G. Wells. Nas três obras, dá-se impulso a processos rememorativos que, embora atenuem o efeito de autenticidade da matéria narrada proposto em Robinson Crusoé, buscam preservar a autoridade e a credibilidade dos narradores-protagonistas. Observa-se que, no caso de A narrativa de Arthur Gordon Pym, o efeito de autenticidade é problematizado com a afirmação, no prefácio atribuído a Pym, de que as primeiras páginas sobre suas aventuras haviam sido escritas por um certo "sr. Poe" e publicadas no jornal Southern Literary Messenger. Em seguida, ainda no prefácio, Arthur Gordon Pym esclarece que o público leitor se recusa a aceitar a natureza ficcional do texto sugerida por aquele sr. Poe, o que autoriza Pym a alcançar a inferência de que seu relato merece confiança: "Disso concluí que os fatos de minha narrativa eram de natureza tal que traziam consigo prova suficiente de sua autenticidade, e que portanto eu tinha pouco a perder no que respeitava à incredulidade popular." 11

Se, em Robinson Crusoé, o narrador-protagonista pretende se apresentar como pleno definidor dos sentidos do texto, em $A$ narrativa de Arthur Gordon Pym, o leitor passa a participar, consoante anotado

${ }^{10}$ DEFOE. Robinson Crusoé, p. 117, grifo nosso. "And now it was when I began to keep a Journal of every Day's Employment, for indeed at first I was in too much Hurry, and not only Hurry as to Labour, but in too much Discomposure of Mind, and my Journal would ha' been full of many dull things: For Example, I must have said thus. Sept. the 30th. After I got to Shore and had escap'd drowning, instead of being thankful to God for my Deliverance, having first vomited with the great Quantity of salt Water which was gotten into my Stomach, and recovering my self a little, I ran about the Shore, wringing my Hands and beating my Head and Face, exclaiming at my Misery, and crying out, I was undone, undone, till tyr'd and faint I was forc'd to lye down on the Ground to repose, but durst not sleep for fear of being devour'd." (DEFOE. Robinson Crusoe, p. 60, grifo nosso).

${ }^{11}$ POE. A narrativa de Arthur Gordon Pym, p. 16. "I thence concluded that the facts of my narrative would prove of such a nature as to carry with them sufficient evidence of their own authenticity, and that I had consequently little to fear on the score of popular incredulity." (POE. The Narrative of Arthur Gordon Pym of Nantucket, p. vii). 
por Pym, da construção de significações do relato, conferindo um selo de autenticidade àquilo que, a princípio, seria tomado por uma narrativa ficcional escrita pelo "sr. Poe". Diante da autoridade conferida ao narrador-protagonista do romance de Poe, perfila-se o respaldo conferido ao stevensoniano Jim Hawkins, narrador-protagonista de $A$ ilha do tesouro. Suas recordações sobre a aventura experimentada em viagem e durante a frenética estadia na ilha contam com a chancela e com o encorajamento de representantes da nobreza e da elite econômica inglesa, como se depreende logo ao início do texto:

O Proprietário Rural, Conde Trelawney, o Dr. Livesey e o resto dos cavalheiros me pediram para escrever o relato completo da história da Ilha do Tesouro, do seu início até o seu final, não deixando nada de fora, exceto a localização da ilha; e isto somente porque ainda lá se encontra parte do tesouro que não foi transportada; assim eu tomo da pena no Ano da Graça de 17—. ${ }^{12}$

A busca do efeito de autenticidade, problematizada por Edgar Allan Poe em A narrativa de Arthur Gordon Pym, é significativamente amortizada em $A$ ilha do dr. Moreau. Charles Edward Prendick, sobrinho do narrador-protagonista, elabora uma nota introdutória ao manuscrito por este deixado. $\mathrm{O}$ herdeiro não busca advogar pela memória do tio, afirmando que os eventos por ele registrados teriam de fato ocorrido. Resta-lhe dispor, por isso, da prerrogativa de semear dúvidas e as transmitir ao leitor:

Assim, os fatos principais da narrativa que se segue não têm nenhuma confirmação. Desde que isto fique bem entendido, não vejo nenhum mal em colocá-la à disposição do público, obedecendo assim, segundo creio, às intenções do meu tio. Há pelo menos um fato dando apoio a sua história: ele desapareceu das vistas da humanidade a cerca de 5 graus de latitude Sul e 105 graus de longitude Oeste, e reapareceu naquela mesma região depois

\footnotetext{
${ }^{12}$ STEVENSON. A ilha do tesouro, p. 13. "Squire Trelawney, Dr. Livesey, and the rest of these gentlemen having asked me to write down the whole particulars about Treasure Island, from the beginning to the end, keeping nothing back but the bearings of the island, and that only because there is still treasure not yet lifted, I take up my pen in the year of grace 17-." (STEVENSON. Treasure Island, p. 13).
} 
de transcorridos onze meses. De alguma maneira ele conseguiu sobreviver durante esse intervalo. ${ }^{13}$

É de se notar que os romances de Daniel Defoe, Edgar Allan Poe, Robert Louis Stevenson e H. G. Wells guardam em comum, para além da apresentação de espaços narrativos insulares, ponderações relacionadas ao efeito de autenticidade do texto e à celebração do pacto ficcional. Pode-se afirmar que essas ponderações se comunicam com a maneira como o gênero romanesco foi gradualmente construído e trabalhado, e podem ser verificadas para além das fronteiras pertinentes às literaturas de língua inglesa.

Dialogando com o efeito de autenticidade buscado no enredo de Robinson Crusoé e, indiretamente, com a ideia de "realismo formal", ${ }^{14}$ associada por Ian Watt à ascensão do romance, o escritor argentino Adolfo Bioy Casares participa da discussão sobre a historicidade do gênero romanesco ao apresentar proposições bastante diversas em 1940, quando da publicação de La invención de Morel. Um dos mecanismos utilizados por Bioy para lançar luz sobre a historicidade dos gêneros literários consiste no estabelecimento de sucessivos contrastes e aproximações entre os romances Robinson Crusoé e La invención de Morel, o que posteriormente vem a repercutir no conto "Un perro que se llamaba Dos", publicado em 1948. A reflexão sobre o efeito de autenticidade se instaura em La invención de Morel pela apresentação, no rol de personagens, de um editor que a si arroga a faculdade de comentar o texto escrito pelo narrador-protagonista e de colocar em dúvida as informações por este ofertadas. A partir da relação de divergência entre narrador-protagonista e editor, Bioy confronta a ideia de autenticidade do relato e opera de modo a inibir inclinações ao estabelecimento de correspondências entre

${ }^{13}$ WELLS. A ilha do dr. Moreau, p. 15-16. "So that this narrative is without confirmation in its most essential particular. With that understood, there seems no harm in putting this strange story before the public in accordance, as I believe, with my uncle's intentions. There is at least this much in its behalf: my uncle passed out of human knowledge about latitude $5^{\circ} \mathrm{S}$. and longitude $105 \mathrm{E}$. [sic], and reappeared in the same part of the ocean after a space of eleven months. In some way he must have lived during the interval." (WELLS. The Island of Dr. Moreau, p. vi).

${ }^{14}$ WATT. A ascensão do romance, p. 34. 
o que é redigido pelo narrador-protagonista - uma espécie de "náufrago voluntário" 15 - e o que é por ele vivenciado nos limites do romance.

A fragilização da autoridade do narrador para expor as próprias experiências é levada ao limite por Adolfo Bioy Casares em 1945, ano de publicação de Plan de evasión. Nesse romance, verifica-se, a exemplo do observado em La invención de Morel, um entrecruzamento das vozes de dois personagens: de um lado, tem-se Enrique Nevers, o protagonista que escreve cartas sobre episódios ocorridos em ilhas venezuelanas; de outro, seu tio Antoine, destinatário que não apenas lê as missivas como também edita as informações enviadas por Nevers. Ocorre que, em Plan de evasión, a perspectiva do editor assume tamanha força que não se restringe ao espaço de notas de rodapé acrescidas às cartas do sobrinho. A interpretação de Antoine acerca do conteúdo redigido pelo protagonista acaba por avançar o corpo do texto e por consistir em fonte primeira de acesso à ação transcorrida nas ilhas governadas por Castel. $\mathrm{O}$ editor chama a si, desse modo, a função narrativa que a princípio seria desempenhada por Nevers.

Ao conduzir, para o cerne da narrativa, aspectos pertinentes a modulações históricas do gênero romanesco e ao efeito de autenticidade do texto literário, Bioy não apresenta objetos inéditos de discussão. De toda sorte, a maneira como o escritor argentino se dispõe a abordar aqueles aspectos ganha relevo por interpelar elementos consolidados em Robinson Crusoé e trabalhados posteriormente em obras como A narrativa de Arthur Gordon Pym, A ilha do tesouro e $A$ ilha $d o d r$. Moreau. Enquanto, nesses romances, a autoridade narrativa é delineada à medida que os protagonistas avançam por territorialidades que tomam por desconhecidas, em La invención de Morel, parte-se de premissa oposta, segundo a qual não há o que desbravar. Tudo está mapeado, registrado, atestado, segundo afirma o náufrago voluntário ao manifestar sua intenção de escrever uma Defesa ante sobreviventes e um Elogio de Malthus: “[...] provarei que o mundo, com o aperfeiçoamento das polícias, dos documentos, do jornalismo, da radiotelefonia, das alfândegas, torna irreparável qualquer erro da justiça, é um inferno unânime para os perseguidos." 16 Não havendo espaço físico a explorar, resta aos

${ }^{15}$ LAFON. Hoy, en esta isla, p. 155.

${ }^{16}$ BIOY CASARES. Obras completas de Adolfo Bioy Casares, p. 17. “[...] demostraré que el mundo, con el perfeccionamiento de las policías, de los documentos, del 
protagonistas casareanos o espaço de criação propiciado pela escrita de textos. Note-se, nesse ponto, como Bioy se apropria do espaço narrativo e a ele confere instabilidade, fazendo-o se afigurar como um dos pilares sobre os quais o romance havia sido edificado, conforme a perspectiva de Watt. ${ }^{17}$ É de se observar que, nos dizeres de Watt, a ilha teve seu lugar assegurado naquele pilar:

Defoe parece ser o primeiro dos escritores ingleses que visualizou o conjunto da narrativa como se esta se desenrolasse num ambiente físico real. Seu cuidado com a descrição do ambiente ainda é intermitente, mas os detalhes vívidos conquanto ocasionais suplementam a contínua implicação de sua narrativa e nos levam a relacionar muito mais completamente Robinson Crusoé e Moll Flanders a seus respectivos meios do que fazíamos com as personagens de ficção anteriores. Essa firmeza da ambientação destaca-se particularmente na maneira como Defoe trata os objetos móveis do mundo físico: em Moll Flanders há muito linho e ouro, enquanto a ilha de Robinson Crusoé está cheia de roupas e ferramentas. ${ }^{18}$

Em diálogo com textos da tradição literária de língua inglesa que conferem destaque ao espaço narrativo insular, Bioy assinala que os manuscritos redigidos nas ilhas não visam ao propósito de zelar por uma segura correspondência entre o enunciado do narrador e o que é por ele observado. Ao contrário, realçam o texto como invenção ideada por Morel e pelo "náufrago voluntário", por Nevers e Antoine. Mais que à máquina de captação e reprodução de imagens ou que às celas multicoloridas de Castel, reserva-se à escrita de textos um locus privilegiado naqueles romances.

Por um lado, os manuscritos presentes em La invención de Morel e em Plan de evasión acenam como âmbito propício à acolhida da experiência criativa; por outro, revelam-se como esferas onde essa experiência mesma é submetida à prova. Ao propor uma discussão desse viés naqueles romances, como em alguns de seus contos, Bioy expressa inquietações relativas ao foco e à autoridade do narrador. Com efeito,

periodismo, de la radiotelefonía, de las aduanas, hace irreparable cualquier error de la justicia, es un infierno unánime para los perseguidos." (BIOY CASARES. La invención de Morel, p. 155).

${ }^{17}$ WATT. A ascensão do romance.

${ }^{18}$ WATT. A ascensão do romance, p. 28. 
ele põe em xeque o efeito de autenticidade estimado no contexto de ascensão do romance, como se depreende de trecho de sua resenha sobre o borgiano El jardín de senderos que se bifurcan:

Algumas convenções se formaram por inércia: é habitual (e, em geral, reconfortante) que nos romances não haja aparato crítico; é habitual que todos os personagens sejam fictícios (se não se trata de romances históricos). Outras convenções - a história contada por um personagem, ou por vários, o diário encontrado na ilha deserta - acaso foram um deliberado recurso para aumentar a verossimilhança; hoje servem para que o leitor saiba, imediatamente, que está lendo um romance e para que o autor introduza o ponto de vista no relato. ${ }^{19}$

Em sua trajetória literária, Bioy segue enfrentando questões colocadas a partir do diálogo com narrativas como as de Defoe, Poe, Stevenson e Wells, e o faz para além das fronteiras do gênero romanesco. Assim é que, no conto "Un perro que se llamaba Dos" (El gran Serafin, 1967), o argentino apresenta "[...] a história de um Robinson que teve como ilha um arvoredo, um exíguo monte perdido nos campos do sul. Essa história e algo mais." ${ }^{20}$ Ao transitar pela seara do romance e dali extrair aspectos a que viria a se dedicar no âmbito do conto, Bioy continua a levar em consideração tanto as nuances por meio das quais o espaço narrativo insular e suas modulações se apresentam no despontar do romance, quanto o fato de que a apresentação da ilha, em romances como Robinson Crusoé, se relaciona a um contexto histórico e cultural de louvor ao desbravamento de territórios e ao feito individual.

19 "Algunas convenciones se han formado por inercia: es habitual (y, en general, reconfortante) que en las novelas no haya aparato crítico; es habitual que todos los personajes sean ficticios (si no se trata de novelas históricas). Otras convenciones -la historia contada por un personaje, o por varios, el diario encontrado en la isla desierta - tal vez fueron un deliberado recurso para aumentar la verosimilitud; hoy sirven para que el lector sepa, inmediatamente, que está leyendo una novela y para que el autor introduzca el punto de vista en el relato." (BIOY CASARES. Resenha sobre "El jardín de senderos que se bifurcan", p. 62 apud LEVINE. Guía de Bioy Casares, p. 101, tradução nossa, grifo nosso).

20 "[...] la historia de un Robinson que tuvo por isla una arboleda, un exiguo monte perdido en los campos del sur. Esa historia y algo más." (BIOY CASARES. El gran Serafín, p. 224-225, tradução nossa). 
Em oposição ao herói do texto de Daniel Defoe, o protagonista de "Un perro que se llamaba Dos" não objetiva dominar novos espaços ou auferir vantagens econômicas; em verdade, parte de Buenos Aires para o campo no intuito de se recolher e se dedicar à escrita do que o narrador qualifica como "la obra" - uma ideia referida de maneira tão imprecisa que poderia consistir na "redação de um ou vários volumes" ("redacción de uno o varios volúmenes"), na "concepção de uma doutrina" ("concepción de una doctrina") ou o no "cultivo da mente" ("cultivo de la mente"). ${ }^{21}$ Analisando-se o encadeamento de eventos expostos nas duas narrativas, identifica-se uma diferença significativa entre a causa do insulamento vivenciado por Crusoé e aquele experimentado por Martín Campbell, protagonista do conto casareano: no romance inglês, a estadia de vinte e oito anos em uma ilha se impõe ao protagonista como resultado de viagem interrompida por uma fatalidade; no conto, diversamente, o insulamento se funda em um ato de vontade.

O contraste entre elementos dispostos em Robinson Crusoé e outros presentes em "Um perro que se llamaba Dos" ocorre, ainda, pela fragilização da autoridade do protagonista no que toca à exposição da própria história. Martín Campbell, que pretende dedicar a vida à escrita, não é disposto como titular do relato de seu período de vida no campo. As experiências de Campbell são contadas, sucessivamente, a dois interlocutores. Em um primeiro momento, o próprio Campbell as transmite a Flaco Silva, seu amigo nos tempos de juventude; após, Flaco Silva as relata ao narrador do conto, que, a exemplo do que faz Antoine Brissac em Plan de evasión, procede à organização de informações fornecidas por outrem. Como consequência, relativiza-se no conto tanto a autoridade que se poderia encontrar na voz de Martín Campbell quanto uma fiel correspondência entre os eventos ocorridos e a maneira como são editados por um narrador não nomeado.

Reportando-se a um diálogo entre Martín Campbell e Flaco Silva, quando os amigos já estão idosos, o narrador de "Un perro que se llamaba Dos" desenha um panorama da vida do personagem insulado em uma localidade remota. Nesse panorama, entremeiam-se informações sobre a vida na cidade e no campo, sobre a juventude e a velhice e sobre projetos, expectativas e frustrações confessadas por Campbell. Segundo o narrador do conto, Campbell faz de um bosque a sua ilha e, durante

${ }^{21}$ BIOY CASARES. El gran Serafin, p. 225, tradução nossa. 
o longo período de reclusão, objetiva edificar "la obra". No entanto, de maneira diversa daquela vivenciada por Crusoé, o protagonista do conto casareano não se assenhora do espaço isolado a ponto de ali encontrar uma via de louvor ao feito individual. Conforme assinalado por Flaco Silva ao narrador, Campbell, em sua velhice, só se fazia reconhecer pelos pequenos olhos azuis, ${ }^{22}$ ofuscados pela tez áspera como uma casca de árvore. Com o passar dos anos, o protagonista do conto não prepondera sobre o ambiente onde se recolhe; antes, é mudado e se torna árvore dentre as tantas outras de seu arvoredo. Cumpre notar que o apagamento da personalidade de Campbell e a mescla de sua figura às árvores de seu bosque são precedidos do projeto do protagonista de, após se insular na quinta conhecida como "El Escondido", ${ }^{23}$ entregar-se à atividade intelectual. Seus dias, contudo, são consumidos por dificuldades relativas à consecução de uma série de atividades rurais. ${ }^{24}$

Durante viagem de ônibus, Campbell revela a Flaco Silva que sua única boa lembrança da experiência de insulamento dizia respeito a um cão que lhe fizera companhia durante nove anos e que lhe havia sido presenteado pela filha de um hoteleiro durante estadia em Rauch, pouco tempo antes de sua mudança para "El Escondido". Segundo esclarece Campbell, "[a] filha do dono do hotel lhe deu o nome de Dos, porque eu era um e em El Escondido não haveria outro." ${ }^{25}$. O animal, cujo desenho da pelagem imitava, no focinho, as linhas de um par de óculos, parecia observar Campbell enquanto este falava sozinho. Gradualmente e com notas de crescente complexidade, o cão passou a comentar as observações de seu dono, reservando-se não apenas a função de corroborá-las, mas também a faculdade de quanto a elas dissentir. ${ }^{26}$

Em ensaio sobre os diálogos que se podem estabelecer entre Fausto, de Goethe, e a narrativa casareana, Lisa Block de Behar sustenta que Dos pode ser compreendido como expressão da dualidade existente em Martín Campbell. ${ }^{27}$ Embora a linha de raciocínio proposta por Block

\footnotetext{
22 BIOY CASARES. El gran Serafin, p. 225.

${ }^{23}$ BIOY CASARES. El gran Serafin, p. 226.

${ }^{24}$ BIOY CASARES. El gran Serafin, p. 227.

25 "[1] chica del hotelero lo llamó Dos, porque yo era uno y en el Escondido no habría otro” (BIOY CASARES. Un perro que se llamabado Dos. El gran Serafín, p. 228, tradução nossa).

${ }^{26}$ BIOY CASARES. El gran Serafin, p. 229-230.

${ }^{27}$ BLOCK DE BEHAR. Nuevas versiones de un pacto fáustico, p. 28.
} 
de Behar se invista de razoabilidade, dá-se preferência a outra via de exame do conto, respaldada na vigorosa interlocução que se pode verificar entre "Un perro que se llamaba Dos" e Robinson Crusoé. O diálogo entre as duas narrativas não se resume àquela menção direta ao protagonista do romance de Defoe; em verdade, torna-se mais estreito pelo estabelecimento de uma relação de causalidade que conduz Campbell e Crusoé a caminhos bastante distintos. Em "Un perro que se llamaba Dos", lê-se sobre uma personagem insulada no campo, que objetiva escrever e edificar "la obra". Absorto, contudo, em uma série de tarefas manuais, não procede à escrita e se compraz em entabular conversas com Dos, animal de qualidades extraordinárias que lhe replica. Em passagem de Robinson Crusoé, encontra-se referência a um cão que, como outros animais domésticos, sobreviveu ao naufrágio:

Os dois gatos eu tinha carregado comigo, e o cachorro pulou do navio comigo por conta própria, nadou para a praia e foi atrás de mim no dia seguinte ao que levei para a terra o primeiro carregamento, e foi um fiel companheiro durante muitos anos; tudo o que eu desejava, ele apanhava para mim, e nunca deixou de me fazer companhia, entretanto o que eu queria mesmo era que falasse comigo, mas isso não era possível. Como citei anteriormente, encontrei pena, tinta e papel, que poupei ao máximo, e devo adiantar que, enquanto a tinta durou, mantive um registro exato. ${ }^{28}$

Note-se, nos dois textos, que a possibilidade de interlocução com alguém, ainda que se trate de um cão, é inserida na cadeia de eventos que conduzem ou afastam os protagonistas da situação de escrita. Uma vez confirmado o insulamento pela ausência de comunicação efetiva com uma alteridade, Robinson Crusoé passa à escrita e nela se concentra até que a tinta acabe. Antevista, por outro lado, a perspectiva de discussão em um ambiente a princípio propício ao insulamento, Martín Campbell posterga

\footnotetext{
${ }^{28}$ DEFOE. Robinson Crusoé, p. 111. “[...] I carry'd both the Cats with me; and as for the Dog, he jump'd out of the Ship of himself, and swam on Shore to me the Day after I went on Shore with my first Cargo, and was a trusty Servant to me many Years; I wanted nothing that he could fetch me, nor any company that he could make up to me, I only wanted to have him talk to me, but that he could not do: As I observ'd before, I found Pen, Ink, and Paper, and I husbanded them to the utmost, and I shall shew, that while my Ink lasted, I kept things very exact.” (DEFOE. Robinson Crusoe, p. 56).
} 
o projeto de escrita. Sua obra, especialmente a partir da convivência com Dos, torna-se outra. Da assertiva de que o cão se chamava Dos porque Campbell era um e não havia outro, extraem-se duas implicações: a primeira diz respeito ao fato de que, na quinta tornada ilha, não haveria outro homem que não Campbell. A segunda se relaciona à inexistência de uma entidade que se poderia considerar inferior: não havendo "outro", abre-se caminho à consolidação de uma relação de igualdade de vozes entre Campbell e Dos.

Se à primeira vista é possível traçar um paralelo entre o cachorro Dos e o cão que fizera companhia a Robinson Crusoé, em momento posterior coteja-se o sujeito Dos com Sexta-Feira, o nativo de língua cortada submetido ao senhorio do náufrago inglês. Conquanto possuam naturezas obviamente distintas, ambos os personagens têm suas caracterizações elaboradas a partir de um mesmo ponto nodal, qual seja, aquele referente à constituição da subjetividade a partir do domínio da língua. Não é custoso perceber que, na raiz da entidade Dos e de SextaFeira, se encontra o shakespeariano Calibã, que traz à luz, precisamente, a possibilidade de se expressar pelo uso da linguagem verbal ensinada por Próspero e Miranda. Calibã se torna ameaça a seus senhores por manusear a língua e, com ela, manifestar-se em situação de paridade diante do protagonista e de sua filha. Escravizado e impossibilitado de habitar a ilha em comunhão com Próspero e Miranda, resta-lhe fazer uso da língua aprendida com o propósito de amaldiçoá-los: "CALIBÃ - A falar me ensinastes, em verdade, / Minha vantagem nisso, é ter ficado sabendo como amaldiçoar. Que a peste vermelha vos carregue, / por me terdes ensinado a falar vossa linguagem." 29

Em "Un perro que se llamaba Dos", Adolfo Bioy Casares dispõe personagens em um espaço insulado, mas procede de maneira significativamente distinta da que se verifica nas ilhas de Próspero e Crusoé. O protagonista Martín Campbell vê seu projeto de escrita atravessado, e não passivamente corroborado, por uma entidade que se apropria da língua e, de simples ouvinte ou servo, chama a si a condição

\footnotetext{
${ }^{29}$ SHAKESPEARE. A tempestade, p. 32. "CALIBAN You taught me language, and my profit on't / Is, I know how to curse. The red plague rid you / For learning me your language!" (SHAKESPEARE. The Tempest, p. 58). A respeito de outras possibilidades de cotejo entre as figuras de Calibã e Sexta-Feira, cf. CALVINO. "Robinson Crusoe", o diário das virtudes mercantis, p. 106-107.
} 
de interlocutora. O convívio com Dos impulsiona em Campbell uma mudança: ao invés de dominar o espaço, o proprietário de "El Escondido" se integra ao que está à volta - a escolha de um sobrenome alusivo às palavras "campo" e "belo" é, aliás, sugestiva do processo por que passa o protagonista. O homem se integra ao ambiente a ponto de lembrar, aos olhos do amigo Flaco Silva, o aspecto de uma casca de árvore.

Ao início do conto, Martín Campbell manifesta o desejo de viver em completa dedicação à escrita. Sua "obra", entretanto, não é edificada pela elaboração de textos; consolida-se, na verdade, a partir das trocas estabelecidas com Dos. Campbell se desembaraça, assim, da série de relações hierárquicas ilustrada por Crusoé em relação a Sexta-Feira e por Próspero em seus embates com Calibã. Eis, nisso, o cerne do diálogo entre Bioy e certa faceta da tradição das literaturas de língua inglesa.

\section{Referências}

BIOY CASARES, Adolfo. El gran Serafin. 2. ed. Buenos Aires: Emecé, 1999.

BIOY CASARES, Adolfo. La invención de Morel. 5. ed. Buenos Aires: Emecé, 1972.

BIOY CASARES, Adolfo. Obras completas de Adolfo Bioy Casares. Organização de Daniel Martino. Tradução de Sergio Molina et al. São Paulo: Globo, 2014. v. 1.

BIOY CASARES, Adolfo. Plan de evasión. 6. impr. Buenos Aires: Emecé, 2000.

BIOY CASARES, Adolfo. Resenha sobre "El jardín de senderos que se bifurcan". Sur, Buenos Aires, n. 92, p. 60-65, maio 1942 apud LEVINE, Suzanne Jill. Guía de Adolfo Bioy Casares. Madrid: Editorial Fundamentos, 1982.

BLOCK DE BEHAR, Lisa. Nuevas versiones de un pacto fáustico. In: TORO, Alfonso de; REGAZZONI, Susanna. Homenaje a Adolfo Bioy Casares: una retrospectiva de su obra. Literatura. Ensayo. Filosofía. Teoría de la Cultura. Crítica literaria. Madrid: Iberoamericana; Frankfurt am Main: Vervuert, 2002. p. 23-39. 
BREMER, Francis J. Puritanism. A Very Short Introduction. Oxford, New York: Oxford University Press, 2009.

CALVINO, Italo. "Robinson Crusoe", o diário das virtudes mercantis. In: . Por que ler os clássicos. Tradução de Nilson Moulin. São Paulo: Companhia das Letras, 1993. p. 104-109.

COSTA LIMA, Luiz. O controle do imaginário \& a afirmação do romance: Dom Quixote, As relações perigosas, Moll Flanders, Tristam Shandy. São Paulo: Companhia das Letras, 2009.

DEFOE, Daniel. Robinson Crusoe. Edited with an Introduction by Thomas Keymer. Oxford, New York: Oxford University Press, 2007. (Oxford World's Classics).

DEFOE, Daniel. Robinson Crusoé. Tradução de Domingos Demasi. Rio de Janeiro: Record, 2004.

LAFON, Michel. Hoy, en esta isla. Discours de réception d'Adolfo Bioy Casares à l'Université Stendhal de Grenoble, à l'occasion de son Doctorat "honoris causa" (09 novembre 1993). Sociocriticism, Montpellier, v. VIII, 2, n. 16, p. 153-160, 1994.

LEVINE, Suzanne Jill. Guía de Adolfo Bioy Casares. Madrid: Editorial Fundamentos, 1982.

POE, Edgar Allan. A narrativa de Arthur Gordon Pym. 2. ed. São Paulo: Cosac Naify, 2010. (Coleção Prosa do Mundo).

POE, Edgar Allan. The Narrative of Arthur Gordon Pym of Nantucket. New York: Harper \& Brothers, 1838. Disponível em: <https://archive. org/details/narrativgord00poerich>. Acesso em: 9 set 2014.

SHAKESPEARE, William. A tempestade. In: . Comédias: teatro completo. Tradução de Carlos Alberto Nunes. Rio e Janeiro: Agir, 2008. SHAKESPEARE, William. The Tempest. Edição de Philip Brockbank e Peter Hollindale. London, Basingstoke: Macmillan Education, 1975. (The Macmillan Shakespeare).

STEVENSON, Robert Louis B. A ilha do tesouro. Tradução de William Lagos. Porto Alegre: L\&PM, 2011.

STEVENSON, Robert Louis B. Treasure Island. New York, London: Sterling, 2004. 
WATT, Ian. A ascensão do romance. Estudos sobre Defoe, Richardson e Fielding. Tradução de Hildegard Feist. São Paulo: Companhia das Letras, 2010.

WELLS, H. G. A ilha do dr. Moreau. Tradução, prefácio e notas de Braulio Tavares. Rio de Janeiro: Alfaguara, Objetiva, 2012.

WELLS, H. G. The Island of Dr. Moreau; A Possibility. New York: Stone \& Kimball, 1898. Disponível em: $<$ https://archive.org/details/ islandofdoctormo00welluoft>. Acesso em: 9 set 2014. 